\title{
PERSISTENSI DAN PEMATAHAN DORMANSI BENIH CABAI RAWIT LOKAL MENGGUNAKAN TEKNIK BIO-INVIGORASI BENIH
}

\section{PERSISTENCY AND BREAKING OF SEED DORMANCY IN LOCAL CHILI PEPPER USING TECHNIQUES BY SEED BIO-INVIGORATION}

\author{
Jefi Saputra, Riska Audina Amir, Nur Mumin dan Gusti Ayu Kade Sutariati* \\ Jurusan Agroteknologi Fakultas Pertanian Universitas Halu Oleo \\ Jl. H.E.A. Mokodompit Kampus Hijau Bumi Tridharma Anduonohu, Kendari \\ *E-mail: sutariati69@yahoo.co.id
}

\begin{abstract}
Persistence and Breaking of Local Chilli Seed Dormancy Using Seed Bio-Invigoration Techniques. This study aims to evaluate the persistence of local chilli seed dormancy while evaluating seed bioinvigoration techniques that effectively break the dormancy of local chilli.. The study consisted of two series of experiments, namely: the persistence test of local chilli. seed dormancy (Series 1) was observed descriptively using a germination indicator for several weeks to reach a germination percentage e" $80 \%$. Testing of seed dormancy breakage by seed bio-invigoration technique (Series 2) using a randomized complete design with 3 replications and 7 treatments namely: no treatment (A0), matriconditioning of husk charcoal powder (SAS) + Bacillus sp. CKD061 (A1), matriconditioning SAS + Pseudomonas sp. TBT214 (A2), red brick powder matriconditioning (SBM) + Bacillus sp. CKD061 (A3), matriconditioning SBM + Pseudomonas sp. TBT214 (A4), matriconditioning SAS + Bacillus sp. CKD061 + Pseudomonas sp. TBT214 (A5), and matriconditioning SBM+Bacillus sp. CKD061 + Pseudomonas sp. TBT214 (A6). The results showed that the persistence of local chilli seed dormant cultivars Konsel 1 and Konsel 2 cultivars were 6 weeks. While the dormancy break test on the Konsel 1 cultivar was 2 weeks at A1 treatment with breaking dormancy of $90.00 \%$. While in Konsel 2 cultivar which is 4 weeks in the A6 treatment with breaking dormancy $86.67 \%$ which is significantly different from the control. This study shows that Al treatment can break dormancy of chilli seeds in Konsel 1 cultivar and A6 treatment in Konsel 2 cultivar.
\end{abstract}

Keywords: Bacillus sp. CKD061, local chilli, matriconditioning, Pseudomonas sp. TBT214, seed dormancy

\begin{abstract}
ABSTRAK
Persistensi dan Pematahan Dormansi Benih Cabai Rawit Lokal Menggunakan Teknik Bio-Invigorasi Benih.Penelitian ini bertujuan untuk mengevaluasi persistensi dormansi benih cabai rawit lokal sekaligus mengevaluasi teknik bio-invigorasi benih yang efektif mematahkan dormansi cabai rawit lokal. Penelitian terdiri atas dua seri percobaan yaitu: uji persistensi dormansi benih cabai rawit lokal (Seri 1) diamati secara deskriptif menggunakan indikator daya berkecambah selama beberapa minggu hingga mencapai persentase perkecambahan
\end{abstract}


e" $80 \%$. Pengujian pematahan dormansi benih dengan teknik bio-invigorasi benih(Seri 2) menggunakan rancangan acak lengkap dengan 3 ulangan dan 7 perlakuan yaitu: tanpa perlakuan (A0), matriconditioning serbuk arang sekam (SAS) + Bacillus sp. CKD061 (A1), matriconditioning SAS + Pseudomonas sp. TBT214 (A2), matriconditioning serbuk bata merah $(\mathrm{SBM})+$ Bacillus sp. CKD061 (A3), matriconditioning SBM + Pseudomonas sp. TBT214(A4), matriconditioning SAS + Bacillus sp. CKD061 + Pseudomonas sp. TBT214 (A5), dan matriconditioning SBM + Bacillus sp. CKD061 + Pseudomonas sp. TBT214(A6). Hasil penelitian menunjukkan bahwa persistensi dormansi benih cabai rawit lokal kultivar Konsel 1 dan Konsel 2 yaitu 6 minggu. Sementara uji pematahan dormansi pada kultivar Konsel 1 yaitu 2 minggu pada perlakuan A1 dengan Dormansi Benihsebesar 90,00\%. Sementara pada kultivar Konsel 2 yaitu 4 minggu pada perlakuan A6 dengan Dormansi Benih sebesar $86,67 \%$ yang berbeda nyata dengan kontrol. Penelitian ini menunjukkan bahwa perlakuanA1 dapat mematahkan Dormansi Benih cabai rawit pada kultivar Konsel 1 dan perlakuan A6 pada kultivar Konsel 2.

Kata Kunci : Bacillus sp. CKD061, cabai rawit lokal, dormansi benih, matriconditioning, Pseudomonas sp.

\section{PENDAHULUAN}

Cabai rawit (Capsicum frutescens L.) merupakan tanaman hortikultura yang cukup penting di Indonesia karena merupakan salah satu jenis sayuran buah yang memiliki nilai ekonomis tinggi untuk dikembangkan. Selain rasanya pedas, cabai juga mengandung gizi yang cukup tinggi. Berdasarkan laporan Departemen Kesehatan Republik Indonesia bahwa kandungan gizi dalam $100 \mathrm{~g}$ buah cabai yaitu kadar air 83,0 \%, lemak 0,3\%, protein 3,0\%, karbohidrat 6,6\%, serat 7,0\%, kalori 32,0 kkal, kalsium 15,0 mg, fosfor 30,0 mg, zat besi $0,5 \mathrm{mg}$, vitamin A $15.000 \mathrm{IU}$, thiamin (vitamin B1) 50,0 mg dan riboflavin (Rulahalu et al., 2013) serta kaya akan karotenoid dan vitamin C (Yamamoto, 2013).

Cabai berperanan penting terhadap perekonomian Indonesia, tercatat bahwa pada tahun 2017 cabai merupakan salah satu penyebab inflasi perekonomian Indonesia (BPS, 2018). Produksi tanaman cabai rawit di Sulawesi Tenggara tahun 2015 sebesar $80.783 \mathrm{ku} \mathrm{ha}^{-1}$ (BPS Sultra, 2016), mengalami penurunan yang sangat drastis pada tahun 2016 hingga mencapai $33.126 \mathrm{ku} \mathrm{ha}^{-1}$ (BPS Sultra, 2017). Sementara produksi tanaman cabai rawit, tahun 2017 hanya meningkat sebesar $3 \mathrm{ku} \mathrm{ha}^{-1}$ menjadi $33.129 \mathrm{ku}$ ha $^{-1}$ bila dibandingkan dengan produksi tahun 2016 (BPS Sultra, 2018). Salah satu faktor yang menjadi pembatas rendahnya produktivitas tanaman cabai rendahnya penggunaan benih bermutu. Padahal telah diketahui bahwa penggunaan benih bermutu merupakan kunci keberhasilan dalam budidaya tanaman. Penggunaan benih bermutu rendah oleh petani tidak dapat dihindari, hal ini dikarenakan langkahnya benih bermutu. Meskipun benih tersedia, harganya relatif mahal dan tidak dapat dijangkau oleh petani kecil. Kondisi ini mengharuskan petani tetap menggunakan benih dengan mutu rendah.

Benih cabai rawit lokal memiliki keunggulan dibandingkan dengan benih cabai rawit lainnya, karena benih cabai rawit lokal lebih tahan terhadap hama dan penyakit tanaman serta masa panen yang lebih lama yang dapat mencapai 1-2 tahun, dibandingkan dengan 
cabai lainnya yang hanya bertahan sampai 6 bulan, itupun produksinya sudah sangat rendah. Namun, dalam pengembangannya cabai lokal memiliki permasalahan terutama benih mengalami dormansi sehingga perkecambahan benih tidak seragam dan dapat mempengaruhi waktu tanam cabai. Jäkel and Witzler (2018) melaporkan bahwa kultivar varietas liar capsicum memiliki perkecambahan yang lama. Dormansi benih pada sebagian besar spesies liar Capsicum dipengaruhi oleh metabolik utama (SMs) seperti ABA yang menghambat perkecambahan biji (Sariyildiz et al., 2005; Nambara et al., 2010), dan lignin, secara struktural senyawa pelindung dan hidrofobik dari kulit biji (Tewksbury et al., 2008; Nambara et al., 2010) serta semakin kedap air jika dikeringkan (Carlo \& Tewksbury, 2014). Berdasarkan hal tersebut, maka perlu diketahui lebih lanjut tentang lamanya benih cabai rawit lokal sampai siap ditanam kembali.

Persistensi benih adalah periode simpan pada suhu kamar yang diperlukan benih dari saat panen sampai persentase mencapai $80 \%$ atau lebih, dinyatakan dalam minggu atau waktu yang dibutuhkan benih dalam mengalami pematahan yang non-dorman. Dengan pemberian perlakuan invigorasi benih dapat mengatasi rendahnya produktivitas yang disebabkan benih bermutu rendah. Oleh karena itu, persiapan dan perlakuan benih untuk meningkatkan mutunya sangat penting dilakukan terlebih lagi dengan adanya permasalahan dormansi exogenous pada benih cabai rawit lokal.

Metode yang digunakan untuk memecahkan masalah dormansi benih cabai rawit yaitu dengan perlakuan awal sebelum tanam dengan menggunakan berbagai bahan kimia diantaranya $\mathrm{GA}_{3}, \mathrm{KNO}_{3}, \mathrm{KNO}_{2}$, $\mathrm{H}_{2} \mathrm{SO}_{4}$ yang bertujuan untuk mengatasi dormansi benih pada cabai. Jäkel \& Witzler (2018) melaporkan bahwa teknik invigorasi benih dengan metode priming benih menggunakan senyawa kimia asam giberelin mampu meningkatkan perkecambahan benih hingga 90\% kemudian diikuti perlakuan $\mathrm{KNO}_{3}$ terutama pada benih yang perkecambahannya lama. Namun, penggunaan senyawa kimia tersebut, tidak dapat dijangkau oleh petani lokal karena harganya relatiflebih mahal.

Selain penggunaan senyawa kimia, teknologi invigorasi benih yang menjadi trend pertanian saat ini adalah teknologi invigorasi benih yang integrasikan dengan penggunaan agens hayati. Penelitian relevan telah dilaporkan bahwa, integrasi agens hayati kelompok rizobakteri efektif mematahkan dormansi padi gogo lokal Sultra. Lebih lanjut, Sutariati et al. (2018) menambahkan bahwa bio-invigorasi benih mengunakan Bacillus sp. CKD061 mampu meningkatkan viabilitas dan vigor benih kultivar padi gogo lokal. Perlakuan menunjukan bahwa indeks vigor benih meningkat $133 \%$ pada kultivar Waburi-buri dan 127\% pada kultivar Daindo Mornene bila dibandingkankan dengan kontrol. Penelitian ini bertujuan untuk mengevaluasi persistensi dormansi benih cabai rawit lokal dan untuk mengevaluasi teknik bio-invigorasi benih efektifmematahkan dormansi cabai rawit lokal. 


\section{BAHAN DAN METODE}

Penelitian ini dilaksanakan di Laboratorium Jurusan Agroteknologi Unit Agronomi Fakultas Pertanian Universitas Halu Oleo, pada bulan Maret sampai Juni 2019. Bahan yang digunakan dalam penelitian ini adalah benih cabai rawit lokal Sultra yang baru dipanen (asal Konawe Selatan), rizobakteri Bacillus sp. CKD061, Pseudomonas sp. TBT214, bacto agar, aquades, Trypthic Soy Agar (TSA), $\mathrm{KH}_{2} \mathrm{PO}_{4}$, gliserol, yeast ekstrak, protease pepton, serbuk arang sekam, serbuk bata merah, plastik wrap, tissue, spiritus, aluminium foil, label, alkohol $70 \%$ dan kertas CD. Alat yang digunakan adalah timbangan analitik, jarum ose, germinator IPB 72-1, cawan petri, shaker, pingset, lampu bunsen, gelas ukur, autoclave, laminar air flow cabinet, hand sprayer, botol scott, speader, kamera dan alat tulis menulis.

Penelitian ini terdiri atas dua seri percobaan yaitu: Uji Persistensi Dormansi Benih Cabai Rawit Lokal Sultra (Seri 1) diamati secara deskriptif menggunakan indikator daya berkecambah (DB) benih selama beberapa minggu hingga setiap kultivar yang diuji mencapai persentase perkecambahan e" $80 \%$ (dormansi telah terpatahkan). Pengujian Pematahan Dormansi Benih Benih Cabai Rawit Lokal Menggunakan Teknik Bio-Invigorasi Benih (Seri 2) menggunakan rancangan acak lengkap (RAL) terdiri atas 7 perlakuan yaitu: Tanpa Perlakuan (A0), matriconditioning serbuk arang sekam (SAS) + Bacillus sp. CKD061 (A1), matriconditioning SAS + Pseudomonas sp. TBT214 (A2), matriconditioning serbuk bata merah (SBM) + Bacillus sp.
CKD061 (A3), matriconditioning SBM + Pseudomonas sp. TBT214(A4), matriconditioning SAS + Bacillus sp. CKD061 + Pseudomonas sp. TBT214 (A5), dan matriconditioning SBM + Bacillus sp. CKD061 + Pseudomonas sp. TBT214 (A6). Setiap perlakuan diulang sebanyak tiga kali. Pengujian dilakukan beberapa minggu hingga mencapai persentase perkecambahan e" $80 \%$.

Benih cabai rawit lokal diperoleh di Kabupaten Konawe Selatan. Benih cabai rawit yang baru dipanen dikumpulkan, selanjutnya diekstrasi hingga diperoleh benih cabai rawit, lalu dikeringananginkan untuk dilakukan pengujian awal ( 0 minggu). Selanjutnya benih lainnya dikeringkan dibawah sinar matahari selama 3 hari untuk pengujian selanjutnya. Persiapan rizobakteri dilakukan pada media TSA padat untuk golongan Bacillus sp. dan media King'B padat untuk golongan Pseudomonas sp. dan diinkubasi selama 48 jam. Koloni bakteri yang tumbuh disuspensikan dalam aquades steril sampai mencapai kerapatan populasi $10^{9}$ cfu $\mathrm{mL}^{1}$. Pembuatan media matriconditioning berupa SAS atau SBM, dengan cara menghaluskan bata merah atau arang sekam kemudian disaring pada saringan 0.5 $\mathrm{mm}$. Serbuk hasil penyaringan sebagai media matriconditioning dikeringkan dalam oven selama 24 jam pada suhu $80^{\circ} \mathrm{C}$. Sebelum diberi perlakuan, benih cabai rawit didesinfeksi dengan $\mathrm{NaOCl} 2 \%$ selama 5 menit, selanjutnya dibilas dengan air steril, kemudian dikering anginkan dalam LAFC selama satu jam. Selanjutya benih diberi perlakuan dengan metode bioinvigorasi menggunakan teknik matriconditioning dengan cara mencampur benih dengan media padatan 
SAS atau SBM dan suspensi bakteri dengan perbandingan benih: media: suspensi $=2: 1,5: 1$. Benih yang telah mendapat perlakuan diletakan pada suhu kamar selama 24 jam dan siap digunakan.

Sebanyak 20 butir benih dikecambahkan pada kertas CD lembab dengan metode uji kertas digulung didirikan dengan tiga ulangan (persistensi 0 minggu setelah panen). Jika benih belum berkecambah maka pengujian diulang pada minggu berikutnya hingga benih mencapai daya berkecambah e" $80 \%$ (Seri 1). Percobaan seri 2 merujuk pada percobaan seri 1 yaitu sebanyak 20 butir benih dikecambahkan pada kertas CD lembab dengan metode UKDD) dengan tiga ulangan (persistensi 0 minggu setelah panen). Jika benih belum berkecambah maka pengujian diulang pada minggu berikutnya hingga benih mencapai DB e" $80 \%$ (Seri 2).

Pengamatan dilakukan terhadap viabilitas dan vigor yaitu Daya Berkecambah(DB), Keserempakan Tumbuh (KST) dan Indeks Vigor (IV). DB menggambarkan viabilitas potensial benih (Sadjad et al., 1999), dihitung berdasarkan persentase kecambah normal $(\mathrm{KN})$ pada hari hitungan I dan II. $\mathrm{K}_{\mathrm{ST}}$ menggambarkan vigor benih, dihitung berdasarkan persentase $\mathrm{KN}$ pada hari antara hitungan I dan II. IV menggambarkan vigor kecepatan tumbuh, dihitung berdasarkan persentase KN pada hitungan hari I. Daya berkecambah, keserempakan tumbuh dan indeks vigor dapat dihitung dengan rumus berikut:

$$
\mathrm{DB}=\frac{\sum \mathrm{KN} \text { hitungan } \mathrm{I}+\sum \text { hitungan II }}{\sum \text { Benih yang ditanam }} \times 100 \%
$$

$$
\begin{gathered}
\mathrm{KST}=\frac{\sum \mathrm{KN} \text { hari antara hitungan } \mathrm{I} \text { dan II }}{\sum \text { Benih yang ditanam }} \times 100 \% \\
\mathrm{IV}=\frac{\sum \mathrm{KN} \text { hitungan } \mathrm{I}}{\sum \text { Benih yang ditanam }} \times 100 \%
\end{gathered}
$$

Data hasil pengamatan persistensi pematahan dormansi dianalisis secara deskriptif menggunakan indikator daya berkecambah, sementara data pengujian pematahan dormansi benih dianalisis menggunakan analisis ragam. Hasil analisis yang menunjukkan pengaruh nyata dilanjutkan dengan uji Duncan Multiple Range Test (DMRT) á=0,05.

\section{HASIL DAN PEMBAHASAN}

Hasil penelitian uji persistensi dormansi benih cabai rawit lokal disajikan pada Tabel 1. Sementara hasil uji pematahan dormansi benih cabai rawit lokal kultivar Konsel 1 dan Konsel 2 menggunakan teknik bio-invigorasi benih disajikan pada Tabel 2 dan 3 .

Tabel 1 menunjukkan bahwa persistensi pematahan dormansi benih cabai rawit lokal kuktivar Konsel 1 dan kutivar Konsel 2 terpatahkan secara alami pada 6 minggu setelah panen. Daya berkecambah benih cabai rawit kutivar Konsel 1 sebesar 83,33\% dan Konsel 2 sebesar 80,00\%. Jäkel and Witzler (2018) melaporkan bahwa kultivar varietas liar memiliki perkecambahan yang lama. Benih cabai liar dilaporkan mengalami dormansi benih (Quintero et al., 2018). Dormansi benih di sebagian besar spesies liar Capsicum dipengaruhi oleh metabolik utama(SMs) seperti ABA, regulator tanaman yang menghambat perkecambahan biji (Nambara et al., 2010) dan lignin, secara struktural 
Tabel 1. Persistensi pematahan dormansi benih kultivar cabai rawit lokal

\begin{tabular}{ccc}
\hline \multirow{2}{*}{ Waktu Perkecambahan Benih Setelah Panen (Minggu) } & \multicolumn{2}{c}{ Daya Berkecambah (\%) } \\
\cline { 2 - 4 } & Konsel 1 & Konsel 2 \\
\hline 2 & 5 & 1,67 \\
4 & 33,33 & 11,67 \\
6 & 56,67 & 50 \\
\hline Persistensi Dormansi Benih Cabai Rawit Lokal (Minggu) & 83,33 & 80 \\
\hline
\end{tabular}

Tabel 2. Pematahan dormansi benih cabai rawit lokal kultivar Konsel 1 pada berbagai perlakuan bio-invigorasi benih terhadap viabilitas dan vigor benih

\begin{tabular}{|c|c|c|c|c|c|c|}
\hline \multirow{2}{*}{ Bio-Invigorasi Benih } & \multicolumn{2}{|c|}{ Daya Berkecambah (\%) } & \multicolumn{2}{|c|}{ Keserempakan Tumbuh (\%) } & \multicolumn{2}{|c|}{ Indeks Vigor (\%) } \\
\hline & 0 Minggu & 2 Minggu & 0 Minggu & 2 Minggu & 0 Minggu & 2 Minggu \\
\hline A0 & 0 & $33,33^{c}$ & 0 & $15^{\mathrm{c}}$ & 0 & $3,33^{\mathrm{c}}$ \\
\hline $\mathrm{A} 1$ & 10 & $90^{\mathrm{a}}$ & 3,33 & $85^{\mathrm{a}}$ & 0 & $56,67^{\mathrm{a}}$ \\
\hline A2 & 10 & $71,67^{\mathrm{ab}}$ & 3,33 & $61,67^{\mathrm{ab}}$ & 1,67 & $26,67^{b}$ \\
\hline $\mathrm{A} 3$ & $10 \mathrm{tn}$ & $73,33^{a b}$ & $8,33 \mathrm{tn}$ & $63,33^{a b}$ & $1,67 \mathrm{tn}$ & $35^{b}$ \\
\hline A4 & 10 & $60^{\mathrm{b}}$ & 6,67 & $56,67^{\mathrm{b}}$ & 3,33 & $30^{\mathrm{b}}$ \\
\hline A5 & 18,33 & $80^{\mathrm{ab}}$ & 13,33 & $73,33^{a b}$ & 5 & $33,33^{b}$ \\
\hline A6 & 10 & $81,67^{\mathrm{ab}}$ & 3,33 & $68,33^{a b}$ & 1,67 & $38,33^{b}$ \\
\hline
\end{tabular}

senyawa pelindung dan hidrofobik dari kulit biji (Tewksbury et al., 2008; Nambara et al., 2010) serta semakin kedap air jika dikeringkan (Carlo dan Tewksbury, 2014). Lebih lanjut, Barchenger dan Bosland (2016) melaporkan bahwa capsaicin merupakan metabolisme sekunder yang berperan dalam metabolisme dan merupakan penyebab dormansi pada beberapa kultivar cabai. Penelitian relevan juga dilaporkan oleh Yuningsih and Wahyuni (2015) bahwa 15 varietas tanaman padi memiliki persistensi dormansi yang berbeda-beda.

Tabel 2 menunjukkan daya berkecambah benih cabai rawit lokal kultivar Konsel 1 telah terpatahkan pada minggu kedua pengujian sebesar
90,00\% pada perlakuan matriconditioning serbuk arang sekam + Bacillus sp. CKD061 (A1) yang berbeda dengan tanpa perlakua (kontrol). Hal ini menunjukkan bahwa perlakuan bio-invigorasi benih mampu mempersingkat perkecambahan benih cabai rawit lokal yang secara alami tanpa perlakuan mencapai 6 minggu. Pada pengamatan keserampakkan tumbuh dan indeks vigor tertinggi diperoleh pada perlakuan matriconditioning serbuk arang sekam + Bacillus sp. CKD061 (A1) yang berbeda nyata dengan kontrol (A0).

Tabel 3 menunjukkan bahwa pamatahan dormansi benih cabai rawit lokal Sultra pada kultivar Konsel 2. Hasil penelitian menunjukkan bahwa 
Tabel 3. Pematahan dormansi benih cabai rawit lokal kultivar Konsel 2 pada berbagai perlakuan bio-invigorasi benih terhadap viabilitas dan vigor benih

\begin{tabular}{lcccccccccc}
\hline \multirow{2}{*}{$\begin{array}{c}\text { Bio-Invigorasi } \\
\text { Benih }\end{array}$} & \multicolumn{3}{c}{ Daya Berkecambah (\%) } & \multicolumn{3}{c}{ Keserempakan Tumbuh (\%) } & \multicolumn{3}{c}{ Indeks Vigor (\%) } \\
\cline { 2 - 10 } & 0 minggu & 2 minggu & 4 minggu & 0 minggu & 2 minggu & 4 minggu & 0 minggu 2 minggu & 4 minggu \\
\hline A0 & 1,67 & $11,67 \mathrm{c}$ & $50,00 \mathrm{c}$ & 0,00 & $8,33 \mathrm{c}$ & $31,67 \mathrm{c}$ & 0,00 & $3,33 \mathrm{~b}$ & $5,00 \mathrm{c}$ \\
$\mathrm{A} 1$ & 5,00 & $51,67 \mathrm{ab}$ & $75,00 \mathrm{ab}$ & 3,33 & $46,67 \mathrm{ab}$ & $68,33 \mathrm{a}$ & 0,00 & $33,33 \mathrm{a}$ & $35,00 \mathrm{a}$ \\
$\mathrm{A} 2$ & 8,33 & $48,33 \mathrm{~b}$ & $65,00 \mathrm{bc}$ & 3,33 & $40,00 \mathrm{~b}$ & $53,33 \mathrm{~b}$ & 0,00 & $23,33 \mathrm{a}$ & $25,00 \mathrm{~b}$ \\
$\mathrm{~A} 3$ & $3,33 \mathrm{tn}$ & $41,67 \mathrm{~b}$ & $61,67 \mathrm{bc}$ & $1,67 \mathrm{tn}$ & $36,67 \mathrm{~b}$ & $46,67 \mathrm{~b}$ & $0,00 \mathrm{tn}$ & $21,67 \mathrm{a}$ & $28,33 \mathrm{ab}$ \\
$\mathrm{A} 4$ & 0,00 & $50,00 \mathrm{ab}$ & $68,33 \mathrm{~b}$ & 0,00 & $41,67 \mathrm{ab}$ & $53,33 \mathrm{~b}$ & 0,00 & $25,00 \mathrm{a}$ & $28,33 \mathrm{ab}$ \\
$\mathrm{A} 5$ & 5,00 & $61,67 \mathrm{ab}$ & $81,67 \mathrm{ab}$ & 1,67 & $56,67 \mathrm{ab}$ & $68,33 \mathrm{a}$ & 0,00 & $21,67 \mathrm{a}$ & $23,33 \mathrm{~b}$ \\
$\mathrm{~A} 6$ & 11,67 & $68,33 \mathrm{a}$ & $86,67 \mathrm{a}$ & 5,00 & $61,67 \mathrm{a}$ & $70,00 \mathrm{a}$ & 1,67 & $30,00 \mathrm{a}$ & $35,00 \mathrm{a}$ \\
\hline
\end{tabular}

Keterangan: Nilai rata-rata yang diikuti oleh huruf yang sama pada kolom yang sama menunjukkan tidak berbeda nyata dengan $\mathrm{UJBD}_{\alpha=0,05}$.

parameter daya berkecambah telah terpatahkan pada minggu keempat pengujian sebesar $86,67 \%$ pada perlakuan matriconditioning SBM + Bacillus sp. CKD061 + Pseudomonas sp. TBT214 (A6) sementara pada kontrol (A0) baru mencapai 50\%. Hal ini menunjukkan bahwa perlakuan bio-invigorasi benih mampu mempersingkat perkecambahan benih cabai rawit lokal yang secara alami tanpa perlakuan mencapai 6 minggu (daya berkecambah Konsel 2 pada Tabel 1). Pada pengamatan keserampakkan tumbuh dan indeks vigor tertinggi diperoleh pada perlakuan matriconditioning SBM + Bacillus sp. CKD061 + Pseudomonas sp. TBT214 A6 yang berbeda nyata dengan kontrol (A0). Hal ini menunjukkan bahwa perlakuan invigorasi benih mampu mematahkan dormansi dan menyeragamkan perkecambahan benih.

Penelitian relevan dengan penelitian sebelumnya bahwa inivigorasi benih adalah salah satu metode yang efektif untuk meningkatkan pemunculan dan keseragaman benih yang mengarah kekuatan tumbuh dan peningkatan hasil tanaman (Ozbay, 2018). Lebih lanjut, dilaporkan bahwa invigorasi benih mampu meningkatkan perkecambahan benih okra (Kamal et al., 2016), bunga matahari (Saha dan Mandal, 2016), bawang merah (Patra, 2017) dan kapas (Dayal et al., 2018). Abdullah et al. (2018) melaporkan bahwa perlakuan GA3 6\% dengan periode penyerapan satu jam memberikan hasil paling signifikan untuk persentase perkecambahan. Hal ini membuktikan bahwa teknik priming benih lebih lebih cepat dan efisien untuk memecahkan dormansi dalam biji cabai serta meningkatkan pertumbuhan tanaman.

Lebih lanjut, dilaporkan bahwa invigorasi benih yang diintegrasikan dengan agens hayati mampu meningkatkan perkecambahan benih. Walida et al. (2016) melaporkan bahwa aplikasi perendaman benih dengan PGPR berpengaruh terhadap daya kecambah benih sawi dan cabai rawit. Sutariati et al. (2018) menambahkan bahwa bio-invigorasi benih mengunakan Bacillus sp. CKD061 mampu meningkatkan indeks vigor benih sebesar $133 \%$ pada kultivar Waburi-buri dan 127\% pada kultivar Daindo 
Mornene bila dibandingkankan dengan kontrol. Hal ini dikarena rizobakteri dari golongan Bacillus spp., dan Pseudomonas fluorescens dapat mensintesis IAA, melarutkan fosfat dan menfiksasi nitrogen (Sutariati dan Wahab, 2012). Lebih lanjut dilaporkan bahwa perlakuan matriconditioning serbuk bata merah dan serbuk arang sekam yang diintegrasikan dengan rizobakteri indigenous mampu meningkatkan viabiltas dan vigor benih padi gogo (Sutariati et al., 2016) sekaligus mampu mematahkan dormansi fisiologis pada benih padi gogo (Sutariati et al., 2014).

\section{KESIMPULAN}

Persistensi pematahan dormansi benih cabai rawit lokal Kultivar Konsel 1 dan Konsel 2 patah pada 6 minggu. Sementara perlakuan pematahan dormansi benih cabai rawit menggunakan teknik bio-invigorasi benih pada kultivar Konsel 1 terpatahkan pada minggu kedua diperoleh pada perlakuan A1 dengan daya berkecambah sebesar 90,00\% sementara pada kultivar Konsel 2 terpatahkan pada 4 minggu dengan daya berkecambah pada perlakuan A6 sebesar 86,67\%.

\section{UCAPAN TERIMAKASIH}

Ucapan terima kasih kami ucapkan kepada Direktorat kemahasiswaan, Direktorat Jenderal Pembelajaran dan Kemahasiswaan, Kementerian Riset, Teknologi dan Pendidikan Tinggi Republik Indonesia (Kemenristekdikti-RI) melalui dana Hibah Program Kreativitas Mahasiswa (PKM) tahun 2019 yang telah membiayai penelitian ini.

\section{DAFTAR PUSTAKA}

Abdullah, S.N.A., N.A. Muhammad, and S.N. Hashim. 2017. A preliminary study on pretreatment solutions towards chili seeds germination. Journal of Academia UiTM Negeri Sembilan 5: 61-68.

Barchenger, D.W., and P.W. Bosland. 2016. Exogenous applications of capsaicin inhibits seed germination of Capsicum annuum. Scientia Horticulturae (203): 29-31.

BPS. 2015. Statistik Sulawesi Tenggara 2016. Sulawesi Tenggara.

BPS. 2017. Statistik Tanaman Hortikultura di Sulawesi Tenggara 2018. Sulawesi Tenggara.

Carlo, T.A., \& J.J. Tewksbury. 2014. Directness and tempo of avian seed dispersal increases emergence of wild chiltepins in desert grasslands. J. Ecol. 102: 248-255.

Dayal, A., O.S. Dahiya, R.C. Punia, dan V.S. Mor. 2018. Effect of seed invigoration treatments on seed quality of different picked american cotton (Gossypium hirsutum L.) varieties after fifteen months of controlled storage. International Journal of Agriculture Sciences. 10(11): 6302-6305.

Jäkel, N., \& M. Witzler. 2018. Influence of germination aids on germination of different Capsicum sp. American Journal of Experimental Agriculture. 20(3): 1-7.

Kamal, D., Y. Verma, dan T.N. Tiwari. 2016. Relative efficacy of seed priming with vermi wash, growth regulators and bio-controlling agents in response to germination and invigoration of okra 
(Abelmoschus esculentus L.). Biosci Biotech Res Asia. 20(16):13.

Nambara, E., M. Okamoto, K. Tatematsu, R. Yan, M. Seo and Y. Kamiya. 2010. Abscisic acid and the control of seed dormancy and germination. Seed Sci Res. 20: 55-67.

Ozbay, N. 201). Studies on seed priming in pepper (Capsicum annuum L.). In: Rakshit A., Singh H. (eds) advances in seed priming. Springer DOI 5(12): 209-239

Patra, S. 2017. Effect of pre-storage seed invigoration treatment in onion (Allium cepa L., cv. Agrifound Dark Red) for improved germinability and field performance. Int. $J$. Curr. Microbiol. App. Sci. 6(6): 478-482.

Quintaro, M.F.C., G.C. Oscar, D.S. Pablo, M.S. José, I.G.C. Ana, dan M.G.P. José. 2018. Improving dormancy and germination of Piquín chili pepper (Capsicum annuum var. glabriusculum) by priming techniques. $J$ Cogent Food \& Agriculture. 4(1): 1-14.

Rulahalu, M.A., M.L. Hehanussa, dan L.L. Oszaer. 2013. Respons tanaman cabai besar (Capsicum Annuum L.) terhadap pemberian pupuk organik hormon tanaman unggul. Jurnal Ilmu Budidaya Tanaman. 2(2):2301-7287.

Sadjad, S., E. Murniati, dan S. Ilyas. 1999. Parameter Pengujian Vigor Benih. Dari Komparatifke Simulatif. PT. Grasindo - PT. Sang Hyang Seri, Jakarta. 185 p.

Saha, D., and A.K. Mandal. 2016. Seed invigoration treatments in different seed sizes of sunflower (Helianthus annuus L.) for maintenance of vigour, viability and yield potential. Indian J. Agric. Res. 50(1): 22-26
Sutariati, G.A.K., dan A. Wahab. 2012. Karakter fisiologis dan kemangkusan rizobakteri indigenus Sulawesi Tenggara sebagai pemacu pertumbuhan tanaman cabai. Jurnal Hortikultura. 22(1):57-64.

Sutariati, G.A.K., L.O.S. Bande, A. Khaeruni, Muhidin, La Mudi, and R.M. Savitri. 2018. The effectiveness of preplant seed bio-invigoration techniques using Bacillus sp. CKD061 to improving seed viability and vigor of several local upland rice cultivars of Southeast Sulawesi. Earth and Environmental Science. 122: 1-6.

Sutariati, G.A.K., Khaeruni A., Pasolon YB, Muhidin and La Mudi. (2016). The effect of seed bioinvigoration using indigenous Rhizobacteria to improve viability and vigor of upland rice (Oryza sativa L.) seeds. I $n t . \quad J$. PharmTech Res., 9: 565-573.

Sutariati, G.A.K., Zul'aiza, S. Darsan, L.M.A. Kasra, S. Wangadi, and La Mudi. 2014. Seed invigoration of local upland rice seed to enhance vigour and overcome problems of postharvest physiological dormancy. J. Agroteknos, 4: 1017.

Tewksbury, J.J., K.M. Reagan, N.J. Machnicki, T.A. Carlo, D.C. Haak, and A.L.C. Pe-aloza. 2008. Evolutionary ecology of pungency in wild chilies. Proc. Natl. Acad. Sci. U.S.A. 105: 11808-11811.

Walida, H., A. Putri, dan B.P. Juliani. 2016. Daya kecambah benih sawi (Brassica juncea) dan cabai rawit (Capsicum frutescens $\mathrm{L}$ ) dengan aplikasi pupuk hayati PGPR (Plant Growth Promoting Rhizobacteria). Jurnal Agroplasma (STIPER) Labuhan Batu. 3(2): 1-6. 
Yamamoto, S. 2013. Use of Capsicum frutescens in Weno, Romanum, and Piis islands, Chuuk Atoll, Federated States of Micronesia. Occasional Papers.53:77-89.
Yuningsih AFV and Wahyuni S. (2015). Effective methods for dormancy breaking of 15 newimproved rice varieties to enhance the validity of germination test. International Seminar on Promoting Local Resources for Food and Health, Proceeding ISEPROLOCAL. ISBN: 9786029071184, Bengkulu, 12-13 October, pp: 166-173. 